\title{
Microfilaria in fine needle aspiration smears of neoplastic lesions: a case series
}

\author{
Yadav R $\mathbf{R}^{1}$, Sagar $\mathbf{M}^{2}$, Maurya M.K ${ }^{3}$, A. A Sonkar ${ }^{4}$, Kumar $A^{5}$ \\ ${ }^{1}$ Dr. Rita Yadav, Senior Resident, Department of Pathology, ${ }^{2}$ Dr. Mala Sagar, Associate Professor, Department of \\ Pathology, ${ }^{3}$ Dr. Malti Kumari Maurya, Associate Professor, Department of Pathology, ${ }^{4}$ Dr. AA Sonkar, Professor, \\ Department of Surgery, ${ }^{5}$ Dr. Ashutosh Kumar, Professor, Department of Pathology, all authors are affiliated with King \\ George Medical University, Lucknow, UP, India.
}

Address for Correspondence: Dr. Rita Yadav, Senior Resident, Department of Pathology, KGMU, Lucknow Emailritayadav2003@gmail.com

\begin{abstract}
Filariasis is a major public health problem in south East Asia including India. It is transmitted by bite of culex mosquito and most commonly caused by Wauchereria bancrofti. Conventional mode of diagnosis is demonstration of microfilaria in peripheral blood smear and body fluid. Co-existence of microfilaria with neoplastic lesions are rare. We present herewith 5 interesting cases of neoplastic lesions where microfilaria were coexistent with one case each of non Hodgkin lymphoma, metastatic adenocarcinoma of supraclavicular lymph node, metastatic adenocarcinoma of cervical lymph node, Infiltrating ductal carcinoma of breast, benign phylloides tumor of breast.
\end{abstract}

Keyword: Microfilaria, Non Hodgkin lymphoma, Fine Needle Aspiration Cytology.

\section{Introduction}

Filariasis is a major public health problem in tropical and subtropical countries and it is one of the common endemic disease in India. It was first reported in 1876 by Bancroft in Brisbane and term filarial bancrofti was given in 1977[1]. Heavily infected areas are found in Uttar Pradesh, Bihar, Jharkhand, Andhra Pradesh, Orissa, Tamilnadu, Kerala, and Gujarat. In India it is caused mainly by Wauchereria bancrofti and Brugia malayi.

The life cycle of microfilariae is found in two host. Man is definitive host and female culex mosquito is intermediate host [2]. Filariasis may produce acute as well as chronic clinical manifestations or person may remain asymtomatic in endemic areas $[3,4]$.

Conventional mode of diagnosis is demonstration of microfilaria in peripheral blood smear and body fluid. Due to nocturnal periodicity of species endemic in India, it is difficult to find microfilariae in FNA smears. Incidental detection of filarial organism has been

Manuscript received: $20^{\text {th }}$ February 2017

Reviewed: $28^{\text {th }}$ February 2017

Author Corrected: $8^{\text {th }}$ March 2017

Accepted for Publication: $15^{\text {th }}$ March 2017 reported in cytological smears from almost any part of body. Microfilariae have also been reported in association with various benign and malignant tumors [5]. Microfilariae with malignant lesions is far more rare in cytological literature [6].

Co-existent of microfilariae with neoplastic lesion has been described but it role in tumorogenesis is not explained. It is considered as incidental finding [5].

Here we report 5 cases where microfilariae were detected in routine cytology without clinical suspicion of filariasis. Out of 5 cases one was benign and four was malignant.

These cases were- non hodgkins lymphoma, metastatic adenocarcinoma in left supraclavicular lymph node, metastatic adenocarcinoma in cervical lymph node, infiltrating ductal carcinoma of breast and benign phylloides tumor of breast, 


\section{Case Series}

\section{Case Series}

\section{Case- 1}

A 65 year old male presented with an enlarged left cervical lymph node measuring $3 \times 2 \mathrm{~cm}$ diameter of one month duration. FNAC was done. Alcohol fixed and air dried smears were stained with Hematoxylin eosin stain and Giemsa stain respectively. On microscopic examination smears were highly cellular comprising of monotonous dispersed population of atypical lymphoid cells. Individual tumor cells have high $\mathrm{N}: \mathrm{C}$ ratio, hyperchromatic nuclei and prominent nucleoli at places along with scant cytoplasm. Smears also revealed microfilariae with tumor cells which was identified as microfilariae of W. bancrofti, based on its characteristic cytomorphology that is sheathed larvae with tail tip free from nuclei [Fig- A and B]. A diagnosis of Non Hodgkins Lymphoma with microfilariae of W. bancrofti was made.
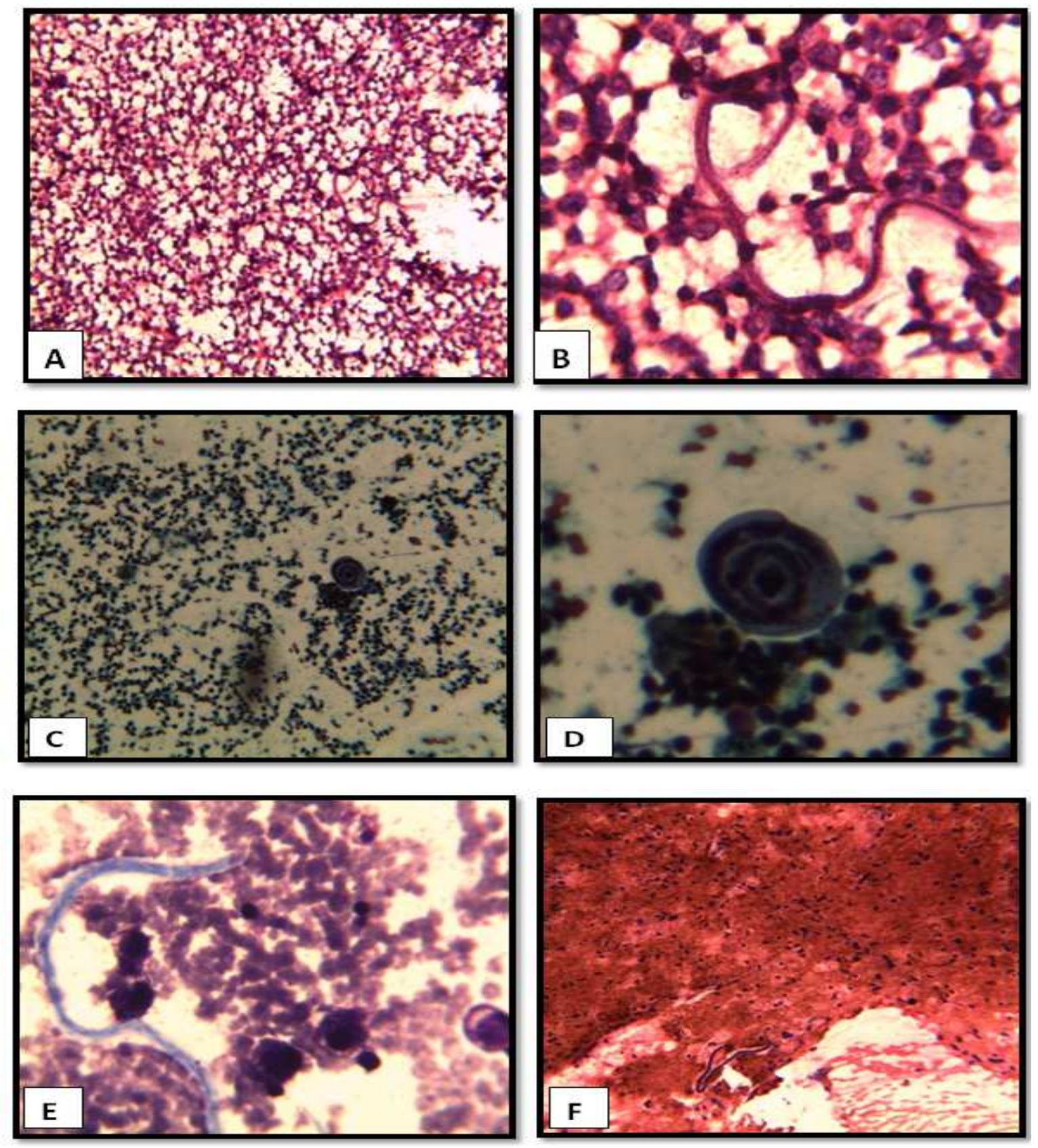

FNA smears reveals microfilariae coexistent with neoplastic lesions (A) (B) Non Hodgkin's lymphoma[H\&E stain,X100, X400], (C) (D) Metastatic adenocarcinoma [PAP stain,X100, X400],, (E) Infiltrating ductal carcinoma of breast[H\&E stain,X400], (F) Benign phylloides tumor of breast [H\&E stain,X100] 


\section{Case- 2}

A 48 year old male presented with an enlarged left supraclavicular lymph node was of size $3 \times 3 \mathrm{~cm}$ diameter of 3 months duration. FNAC was done. Alcohol fixed smears were stained with Hematoxylin eosin stain and Pap stain. On microscopic examination smears were highly cellular comprising of malignant epithelial tumor cells arranged in acinar pattern, groups as well as lying singly in hemorrhagic background. Individual tumor cells have round to oval nucleus, high $\mathrm{N}$ :C ratio, vesicular nuclei with prominent nucleoli and scant amount of cytoplasm. Smears also revealed microfilariae with tumor cells which was identified as microfilariae of W. bancrofti, based on its characteristic cytomorphology that is sheathed larvae with tail tip free from nuclei [Fig- C ]. A diagnosis of Metastatic adenocarcinoma in supraclavicular lymph node with microfilariae of W. bancrofti was made.

\section{Case-3}

A 70 year old male presented with an enlarged right upper cervical lymph node was of size $5 \times 4 \mathrm{~cm}$ diameter of 2 months duration. FNAC was done. Alcohol fixed and air dried smears were stained with Hematoxylin eosin stain and Giemsa stain respectively. On microscopic examination smears shows malignant epithelial cells disposed in clusters as well as lying singly and forming acini in necrotic haemorrhagic background. Individual tumor cells are pleomorphic, high $\mathrm{N}$ : $\mathrm{C}$ ratio, vesicular nuclei with occasional prominent nucleoli and scant to moderate amount of cytoplasm. Smears also revealed microfilariae with tumor cells which was identified as microfilariae of W. bancrofti, based on its characteristic cytomorphology that is sheathed larvae with tail tip free from nuclei [Figure D]. A diagnosis of Metastatic adenocarcinoma in cervical lymph node with microfilariae of $\mathrm{W}$. bancrofti was made.

\section{Case-4}

A 48 year old lady presented with gradually increasing painless left breast lump for 1 month. There was no history of nipple discharge. Breast examination revealed $4 \times 4 \mathrm{~cm}$ sized nodule in left upper outer quadrant with well defined margin, firm in consistency, mobile, the overlying skin was indurated. FNAC was done. Alcohol fixed and air dried smears were stained with Hematoxylin eosin stain and Giemsa stain respectively. On microscopic examination smears showing a malignant epithelial neoplasm disposed in sheets and clusters as well as lying singly in a hemorrhagic background. Individual tumor cells are pleomorphic, have high N:C ratio, vesicular chromatin, inconspicuous to conspicuous nucleoli and moderate amount of amphophilic cytoplasm. Microfilariae are also lying in the background [Fig- E]. A diagnosis of infiltrating ductal carcinoma of breast with filariasis was made.

\section{Case-5}

A 21 year old female presented with slowly growing lump in left breast for 4 month duration. Breast examination revealed lobulated mass measuring $8 \mathrm{X} 7 \mathrm{~cm}$ on size, without skin retraction, firm in consistency, mobile along with no lymphadenopathy. FNAC was done. Blood mixed material aspirate. Alcohol fixed and air dried smears were stained with Hematoxylin- eosin stain and Giemsa stain respectively. On microscopic examination Smears were cellular comprising of ensheathed microfilariae having tail tip free from nuclei and dispersed cells with bare oval and plump spindle nuclei along with occasional ductal epithelial cells in hemorrahgic background [Fig- F]. A diagnosis of benign phylloides tumor of breast with filariasis was made.

\section{Discussion}

Bancroftian filariasis is infection by the filarial worm Wuchereria bancrofti which causes disease by blocking lymphatic vessels. W. bancrofti is responsible for $90.0 \%$ cases of filariasis and is found throughout the tropics and sub-tropical areas world wide. Other uncommon filarial worm are Brugia malayi and Brugia timori[2]. Filariasis produce wide spectrum of clinical manifestations. The acute phase is characterized by fever, lymphangitis, lymphadenitis, epididymo-orchitis, and funniculitis. Eosinophilia and microfilaremia are common in acute phase [3]. Our cases was a retrospective, microfilariae in peripheral blood smear (PBS) was not possible to evaluate. However, absence of microfilariae in PBS does not exclude filarial infection [8]. Chronic stage of filariasis is characterized by lymphadenopathy, lymphadema, hydrocele, and elephantiasis [3]. Some infected individuals remain asymptomatic throughout their life in endemic zones. They are traditionally called as "endemic normal's [4]. 


\section{Case Series}

In our study none of the patients were clinically suspected of filariasis; clinically they presented with breast lump ( 2 cases), lymphadenopathy (3 cases) with clinical suspicion of neoplastic lesion. So these cases come in pathology department for doing fine needle aspiration cytology. A review of literature reveals incidental detection of filarial organism has been reported in cytological smears from almost any part of body. Microfilaria have been detected in breast aspirates [9] lymph node aspirates [10] thyroid aspirates [11] salivary gland aspirates [12] soft tissue nodule [13] bone marrow aspirates [14] brain aspirates [15] lung aspirates [16] pleural fluid [17] pericardial fluid [18], ascitic fluid [19] urine samples [20] cervicovaginal smears, ovarian cyst fluid [21].

Literature reveald microfilariae associated with various neoplastic lesions include non hodgkin's lymphoma, transitional cell carcinoma of bladder, follicular carcinoma of thyroid, seminoma of undescended testis, hemangioma of liver [5], breast carcinoma [22], metastatic adenocarcinoma [23], meningioma, intracranial hemagioblastoma, Fibromyxoma, squamous cell and undifferentiated carcinoma of uterine cervix [24]. In our case series, microfilariae associated with neoplastic lesions included non hodgkins lymphoma, metastatic adenocarcinoma in lymph node, infiltrating ductal carcinoma of breast, benign phylloides tumor of breast. Association of filariasis with neoplasms is often seen although the role in tumorogenesis is controversial. It has been suggested in a few reports that filarial organism may be involved in tumorogenesis by releasing certain toxic mediators or by chronic mechanical irritation at the sites of infestation [5]. Circulating microfilaria obstruct the lymphatics and blood vessels. Due this obstruction extravasation of lymph and blood occurs leading to release of microfilariae. Such obstruction which leads to release of microfilariae may be aggrevated by mechanical blockage by neoplasms or traumatic conditions [20].

\section{Conclusion}

In our case series shows that detection of microfilariae in neoplastic lesion is incidental finding. Role of microfilariae is not known in tumorogenesis, so further studies should be conducted in this contest. Careful screening of cytologic smears should be done for detection of coexistent microfilariae with other benign or malignant lesion to detect the hidden burden of microfilarial disease especially in tropical country like India and to provide accurate treatment.
Funding: Nil, Conflict of interest: None initiated, Permission from IRB: Yes

\section{References}

1. Arora DR, Arora B: Medical Parasitology. 2nd ed, Delhi, SDR, 2005, 184-190

2. Park K. Epidemiology of Communicable Diseases. In Park JE, Park K, (Eds): Textbook of Preventive and Social Medicine, 20 ${ }^{\text {th }}$ ed., Jabalpur, Banarasidas Bhanot, 2005,199-204

3. Meyers WM, Neafi RC, Connor DH. Edited by Binford C.H., Connor D.H. Diseases caused by filarial Nematodes- Bancroftian and Malayan Filariasis Pathology of Tropical and Extraordinary diseases. An Atlas. Vol II. Washington D.C: Armed Forces Institute of Pathology; 1976. p. 340-55.

4. Melrose WD. Lymphatic filariasis: new insights into an old disease. Int J Parasitol. 2002 Jul;32(8):947-60.

5. Gupta S, Sodhani P, Jain S, Kumar N. Microfilariae in association with neoplastic lesions: report of five cases. Cytopathology. 2001 Apr;12(2):120-6.

6. Varghese R, Raghuveer CV, Pai MR, Bansal R. Microfilariae in cytologic smears: a report of six cases. Acta Cytol. 1996 Mar-Apr;40(2):299-301.

7. Gangopadhyay M, Biswas B, Chowdhury M, Deoghoria D. Microfilaria in thyroid aspirate - An unexpected finding. J Cytol. 2011 Oct;28(4):240-1. doi: 10.4103/0970-9371.86366.

8. Agarwal R, Khanna D, Barthwal SP. Microfilariae in a cytologic smear from cavernous hemangioma of the liver. A case report. Acta Cytol. 1998 May-Jun;42 (3):781-2.

9. Kapila K, Verma K. Diagnosis of parasites in fine needle breast aspirates. Acta Cytol. 1996 JulAug;40(4):653-6.

10. Sah SP, Rani S, Mahto R. Microfilariae in lymph node aspirates. Acta Cytol. 2002 Jan-Feb; 46(1): 73-5.

11. Pandit A, Prayag AS. Microfilaria in a thyroid aspirate smear: an unusual finding. Acta Cytol. 1993 Sep-Oct;37(5):845-6. 


\section{Case Series}

12. Sahu KK, Pai P, Raghuveer CV, Pai RR. Microfilaria in a fine needle aspirate from the salivary gland. Acta Cytol. 1997 May-Jun;41(3):954.

13. Pandit AA, Shah RK, Shenoy SG. Adult filarial worm in a fine needle aspirate of a soft tissue swelling. Acta Cytol. 1997 May-Jun;41(3):944-6.

14. Sharma S, Rawat A, Chowhan A. Microfilaria in bone marrow aspiration smears, correlation with marrow hypoplasia: a report of six cases. Indian $\mathbf{J}$ Pathol Microbiol 2006; 49(4): 566-8.

15. Aron M, Kapila K, Sarkar C, Verma K. Microfilariae of Wuchereria bancrofti in cyst fluid of tumors of the brain: a report of three cases. Diagn Cytopathol. 2002 Mar;26(3):158-62.

16. Avasthi R, Jain AP, Swaroop K, Samal N. bancroftian microfilariasis in association wih pulmonary tuberculosis. Report of a case with diagnosis by fine needle aspiration. Acta Cytol 1991; 35(6): $717-8$

17. Marathe A, Handa V, Mehta GR, Mehta A, Shah PR. Early diagnosis of filarial pleural effusion. Indian J Med Microbiol. 2003 Jul-Sep;21(3):207-8.
18. Charan A, Sinha K. Constrictive pericarditis following filarial effusion. Indian Heart J. $1973 \mathrm{Jul}$; 25(3):213-5.

19. Mehrotra R, Gupta OP, Gupta RK. Filarial ascites clinically mimicking malignancy. Acta Cytol. 1996 Nov-Dec;40(6):1329-30.

20. Vassenwala SM, Khan AA. Microfilaria in urinary sediment smears in association with carcinoma of urinary bladder.Report of two cases with review of literature. J Cytol 1990; 7:19-21.

21. Walter A, Krishnaswami H, Cariappa A. Microfilariae of Wuchereria bancrofti in cytologic smears. Acta Cytol. 1983 Jul-Aug;27(4):432-6.

22. Atal P, Choudhury M, Ashok S. Coexistence of carcinoma of the breast with microfilariasis. Diagn Cytopathol. 2000 Apr;22(4):259-60.

23. Kolte SS, Satarkar RN,Mane PM. Microfilaria concomitant with metastatic deposits of adenocarcinoma in lymph node fine needle aspiration cytology: A chance finding. J Cytol. 2010 Apr; 27(2): 78-80.

24. Agarwal PK, Srivastava AN, Agarwal N. Microfialria in association with neoplasms. A report of six cases. Acta Cytol 1982; 26: 480-90.

\section{How to cite this article?}

Yadav R, Sagar M, Maurya M.K, A. A Sonkar, Kumar A. Microfilaria in fine needle aspiration smears of neoplastic lesions: a case series. Trop J Path Micro 2017;3(1):62-66.doi: 10.17511/jopm.2017.i1.11. 